ISSN 1996-1073

www.mdpi.com/journal/energies

Article

\title{
Greening Public Buildings: ESCO-Contracting in Danish Municipalities
}

Jesper Ole Jensen ${ }^{1}$ *, Susanne Balslev Nielsen ${ }^{2}$ and Jesper Rohr Hansen ${ }^{1}$

1 Department of Town, Housing and Property, Danish Building Research Institute, A.C.Meyers

Vænge 15, Copenhagen DK-2450, Denmark; E-Mail: jer@sbi.aau.dk

2 Department of Management Engineering, Technical University of Denmark, Bygning 424, Kongens Lyngby DK-2800, Denmark; E-Mail: sbni@dtu.dk (S.B.N.)

* Author to whom correspondence should be addressed; E-Mail: joj@sbi.aau.dk; Tel.: +45-9940-2358.

Received: 27 February 2013; in revised form: 11 April 2013 / Accepted: 24 April 2013 /

Published: 6 May 2013

Abstract: This paper presents current research on Danish municipalities' use of Energy Service Companies (ESCO) as a way to improve the standard of public buildings and to increase energy efficiency. In recent years more and more municipalities have used ESCO-contracts to retrofit existing public buildings, and to make them more energy efficient. At the moment 30 municipalities (of the 98 municipalities in Denmark) are involved in, or preparing, ESCO contracts. Nevertheless, ESCO-contracting still faces many challenges on the Danish market, as there is a widespread skepticism towards the concept amongst many stakeholders. The purpose of this paper is to discuss the various experience gained so far by municipalities use of ESCO-contracting, the different approached to ESCO-contracting being used in practice, as well as the different viewpoints drivers and barriers behind the development. The strong growth in ESCO-contracts reflects that the ESCO-concept fits well with a number of present problems that municipalities are facing, as well as a flexible adaptation to the local context in different municipalities.

Keywords: Energy Service Companies (ESCO); municipalities; public buildings; energy savings 


\section{Introduction}

\subsection{Definition}

According to the EU-directive on energy end-use efficiency and energy services [1] an energy service company (ESCO) is defined as:

"a natural or legal person that delivers energy services and/or other energy efficiency improvements measures in a users' facility or premises, and accepts some degree of financial risk in doing so. The payment for the service delivered is based (either wholly or in part) on the achievement of energy efficiency improvements and on the meeting of the other agree performance criteria".

In an ESCO contract the ESCO-provider takes the risk for achieving defined energy savings instead of the client (e.g., a building owner), making investments in energy savings measures more calculable and thereby attractive for the client.

Practical definitions of ESCO however vary across Europe [2] and the rest of the World [3,4]. As an alternative, "Energy Savings Performance Contracts" (ESPC) are often used to characterize models for energy services. A major distinction of models is between "Shared savings" and "Guaranteed savings" that concerns different distributions of investments and savings between the client and the ESCO-provider [3,4]. In short, projects using the shared savings model is based on full financing from the ESCO-provider, who in return get a share of the savings - in contrast, projects using the guaranteed savings model are typically financed by the client, where payments include money for the ESCO-provider to implement and operate solutions, as well as guaranteeing the client a certain level of energy savings over a longer period. The shared savings model is mainly used in developing countries where clients have limited access to capital, whereas in a European context, the guaranteed savings model is predominant $[2,4]$.

In the ESCO model used in Danish municipalities, the client provides the investment (i.e., no private or third-party financing), and the ESCO-supplier implements the energy retrofitting initiatives, and guarantees the agreed level of energy savings. "Energy Performance Contracting" (EPC) would therefore be a more correct term to use, like in Sweden where similar types of contracts are used by the municipalities [5]. As "ESCO" however is used widely in a Danish context, the paper will also use this term. Throughout the paper we will use the term "ESCO-provider" for the ESCO-companies, and "ESCO-contract" for the business model, i.e., the ESCO-contract between the client and the provider.

\subsection{Background}

ESCO contracting can be seen as a new approach to implement energy saving measures in existing buildings. Although the concept is more than 100 years old [4], it is only within the recent decade that it has actually gained growth on the European market [4,5]. Especially in Germany, Austria, UK, Spain and Hungary ESCO-providers have firmly established themselves on the market for energy retrofitting of buildings, whereas in other European countries the ESCO-market is still developing. The Danish market for ESCO-contracting is rapidly increasing, also compared to other EU-countries [6]. This is mainly due to growth in ESCO-projects on municipal buildings, where approximately 
30 municipalities (out of 98 municipalities in Denmark) have signed ESCO-contracts or are preparing to do so.

On a national level, ESCO-contracting has been promoted and encouraged in different policy papers on energy savings in the existing building stock. It is seen as an essential input for reaching international as well as national goals on energy savings and $\mathrm{CO}_{2}$ reductions (including the European 20-20-20 goals). As in other countries, the EU Directive on the Energy Performance of Buildings has been a driver for governments to encourage development of energy services, as well as the EU Directive on energy end-use efficiency and energy services has encouraged governments' motivation for setting energy saving targets and practicing energy efficient procurement [2].

The Danish Government signed a political agreement in 2005 as part of the Directive on the Energy Performance of Buildings, where the main objective was statutory energy labeling of both public and private buildings. To encourage energy savings, the municipalities were allowed to take out loans for the renovation, if they included the energy improvements outlined in the energy label for the buildings, as well as other specified energy reducing initiatives. Normally, municipalities are not allowed to start building projects by taking on loans, as a way for the state to keep municipal taxes under control. This ability to loan-finance improvements on municipal buildings was a main carrot for the municipalities to engage in energy savings, either as in-house projects or ESCO-projects. As in other countries, for instance the US, the borrowing capability of public institutions has been very important for the growth of ESCO-providers and performance contracting. Another change in the framework for energy retrofitting was an agreement from 2007 between the municipalities association "Local Government Denmark" and the government settling that all initiatives for energy efficiency with low payback time ( $<$ five years) outlined in the energy label on public buildings should be completed within four years.

As municipal loans have low interest rates third-party financing has not been interesting for the Danish municipalities in ESCO contracting. The guaranteed savings in the ESCO-contract will cover the mortgages on the loan, and the municipality can therefore complete energy renovations as expense neutral.

Municipalities can be seen as locomotives for ESCO-contracting in Denmark, and the municipalities' experience with ESCO-contracting is likely to influence the rest of the ESCO market. Therefore, it is interesting to look at the experience with municipal ESCO-contracts so far, and to understand the drivers and barriers for the development in the municipalities. Although public building accounts for only $5 \%$ of all buildings, municipalities are increasingly becoming central actors in achieving carbon neutral cities, and ESCO-contracting holds many potential lessons for the municipalities to perform "Urban Climate Governance" [7,8]. This might contain learning how to practically manage energy reductions in existing municipal buildings, including implementation as well as operation, monitoring of consumption, training of staff, documenting energy savings, etc., but also to act as facilitators of networks between local stakeholders on implementing energy reductions in other types of buildings, e.g., social housing, private housing and commercial properties. Besides assessing ESCO-contracting on the amount of energy saved, we suggest that ESCO-contracting could also become a learning process for municipalities, enabling and encourage public administrations to work in with public-private and public-public partnerships on energy savings. Other researchers have focused on the "soft" sides of ESCO-contracting, pointing to the collaboration between the in-house staff and the ESCO-provider [9], as well as partnerships and trust between the two parties as central issues for successful 
ESCO-contracting [10]. Our focus is the motivation and the conceptualization of the ESCO projects, and to what extent the partnerships lead to innovation in the municipality FM organization.

ESCO-contracting is, however, in many respects a new way of collaborating for Danish municipalities, and therefore includes many real and perceived challenges. There is still a widespread skepticism towards the ESCO-concept amongst many municipalities, consultants and other stakeholders, and debates are going on between municipalities on the pros and cons of ESCO-contracting. This include views on the transaction costs related to ESCO-contracting and about the economic viability of the ESCO-model, especially in comparison with managing the energy retrofitting of municipal buildings as an entirely in-house project. This partly answers the question, why it has taken time for the ESCO-model to gain momentum. As we mainly see the market as defined by the demand-side, it is important to understand the background and motivation for municipalities to enter ESCO-contracting, but also to understand the skepticism from other municipalities.

\subsection{Purpose and Methodology}

The paper aims at describing the Danish ESCO-market for municipal buildings, and to identify the experiences amongst the municipalities so far, whether the expectations have been met so far, and risks and challenges the municipalities have experienced. This is based on studies of the first ten ESCO-projects in Danish municipalities. Planners and civil servants in these municipalities have been interviewed about the specific background for their ESCO-project, including the motivations for the municipality to take up ESCO-contracting, and their experiences so far. Parallel to this, other informants have been interviewed about their view on ESCO-contracting in Danish municipalities, including two ESCO-providers, one ESCO-consultant and one municipality that has considered, but given up ESCO-contracting. The interviews are based on a semi-structured interview-guide, focusing on motivations and experiences with ESCO-contracting. To research the motivations we asked about the origin of the idea of introducing an ESCO-project, who came up with the idea and why they considered it a good idea compared to what they did already. Their experiences we researched by asking about the project, its characteristics, its organizations and their experiences so far. To explore their learning process we included questions like: what are you most proud of? And has there been surprises along the way which you have learned from or things you would do different if you got the chance? Besides the interviews, the study included surveying of existing Danish ESCO-projects, and international literature studies of ESCO-experiences.

By applying a mainly qualitative research method One issue of the study is the flexibility of the ESCO-concept in relation to the different municipal agendas and contexts (political, financial, organisational, technical etc.), as well as the approach and ambitions from the municipalities. This include a discussion of integrating energy savings and building improvements in the ESCO contract, and to what extent the municipal facilities management function is able to learn from the ESCO-project. Also, the study focused on limits and barriers for ESCO-contracting, identifying the skepticism towards the concept, and discussing whether it could be promoted more actively by the national state. 


\section{Results}

\subsection{An Overview of EPC in Danish Municipalities}

The first ESCO-contract in a Danish municipality was signed in 2006 (by the municipality of Kalundborg). Due to the municipal structure reform in 2007 (which reduced the number of municipalities in Denmark from 279 to 98), the collaboration was delayed, but re-started in 2009. Meanwhile, two other municipalities, Gribskov and Middelfart, had started their own ESCO projects. These three municipalities formed their own "ESCO network", with close collaboration and knowledge-sharing in the initial phases, leading to several ideas on how the ESCO-concept could be disseminated to other municipalities. From 2010, several other municipalities have signed ESCO-contracts, or are preparing a tender for this purpose.

The Danish market has been dominated by private companies that gained experience from ESCO-contracting in neighbouring countries, primarily Sweden. It should be noted that a single ESCO-provider (Schneider Electric) has a large share of the market (approximately half of all contracts so far), although several other ESCO-providers have been present on the market for some time. Several consulting companies have developed competences on ESCO-contracting, and taken on the role as consultants for the municipalities on assessing saving potentials and designing the ESCO-tender. In contrast to many other European countries [2], utilities have not played any large role as providers of ESCO services.

The project periods in the contracts are typically between 8 and 10 years. In all cases the municipalities finance the retrofitting, and the ESCO-provider guarantees a certain energy reduction. If the guaranteed savings are not met, the ESCO-provider will pay the client the difference. If the ESCO-provider saves more that guaranteed, the contract specifies how this surplus is shared between the ESCO-provider and the client. Other typical features in the ESCO-contracts include Energy Labelling of the municipal buildings and training of the municipal staff.

Figure 1 shows key figures from the ten Danish municipalities studied in this project. These ten municipalities were amongst the first to sign a contract. The projects are almost all in the operation phase.

\subsection{Type of Projects}

There is a large variation in the number of buildings included in the ESCO-contracts (from 10 to 260), with an average of 60 buildings (or 122,000 $\mathrm{m}^{2}$ ) per contract. Moreover the investments in the buildings varies, from $22 € / \mathrm{m}^{2}$ to $89 € / \mathrm{m}^{2}$, with an average of $49 € / \mathrm{m}^{2}$. The guaranteed energy savings in the contracts ranges from 16 to $31 \%$, with an average of $21 \%$. This is similar to the saving levels on the Swedish ESCO-market, but might be low in a global perspective, where saving potentials up to $50 \%$ in public buildings have been reported [3]. Our analysis of the Danish cases shows that the guaranteed savings are influenced by a number of factors, and not only the investments per $\mathrm{m}^{2}$. These factors include:

- The standard of the buildings at the outset; well-maintained buildings (e.g., Høje Taastrup) generally reduces the guaranteed energy savings; 
- The volume of buildings included in the contract; if only buildings with a high energy saving potential are included in the contract, this will increase the guaranteed energy savings. On the other hand, including very few buildings will increase transaction costs (e.g., Kalundborg);

- The degree of building improvements in the ESCO-contract; if long-term energy savings or general improvements on the buildings are included, the investments will increase, but the guaranteed savings might not be remarkably higher.

Figure 1. Investments $\left(€ / \mathrm{m}^{2}\right)$, guaranteed savings $(\%)$ and building volume $\left(10,000 \mathrm{~m}^{2}\right)$ in the ten municipalities ESCO-projects, where the blue, red and green lines indicated the average levels.

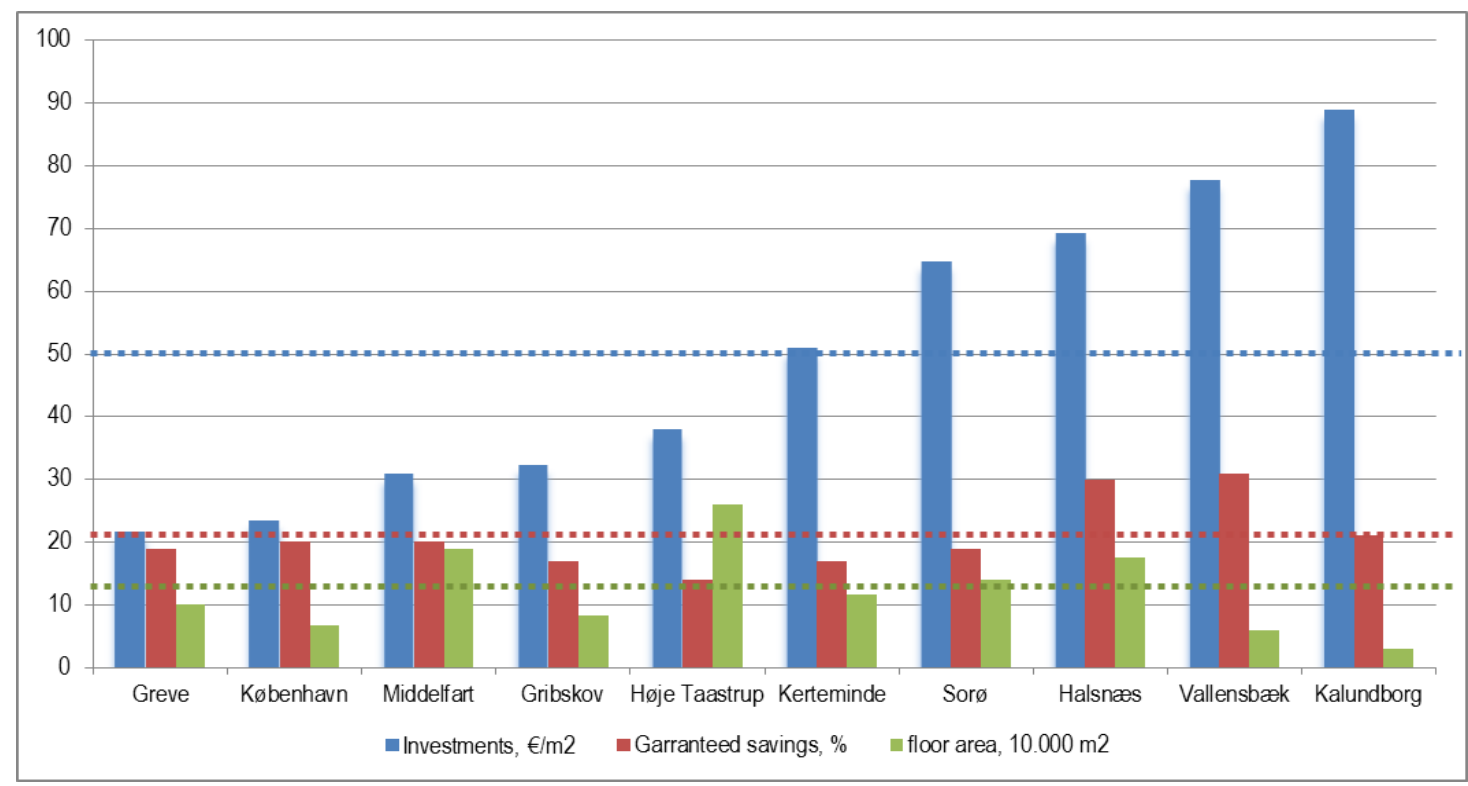

Looking closer at the municipal ESCO-projects in practice, they are different in relation to technologies, economy, ambitions, etc., and subsequently in the way the process is organized. We have elsewhere identified three different approaches to ESCO-contracting [11]:

\section{The basic ESCO-approach:}

This includes replacement of installations and regulation of energy systems and services like CTS control, monitoring, light steering, heat regulation, etc. Technologies are simple and relatively inexpensive but with high energy-saving potential and a short payback period. This only occasionally involves improvements of the building envelope.

Several municipalities (Kalundborg, Middelfart, Gribskov, København, Greve and Vallensbæk) are using such an approach, with short pay-back times and relatively low investments. These projects do not include for instance better insulation of the buildings-related improvements in terms of insulation. As illustrated in Figure 1, these projects are in the lower end of the volume-scale, in terms of total investments and total building volume (below 7 million $€$ and 100,000 $\mathrm{m}^{2}$ floor area). Also measured per $\mathrm{m}^{2}$ the investments are lower for the municipalities having chosen the basic model, except for the municipality of Vallensbæk and Kalundborg. The high expenses for Kalundborg municipality reflect that it was the first municipality to implement an ESCO-project, and that they included only ten buildings. This means that the transaction costs have become relatively high, leading to high 
investments per $\mathrm{m}^{2}$. The absence of internal competences in the municipality on certain assignments meant the municipality had to buy these competences from external parties, which was expensive for the municipality:

"We have bought simple supervision ... as there were no competences on these areas in the municipality, we had to buy all things from consultants. I'm not blaming the consultants, but the municipality, as they have cut down on all these areas." (civil servant, municipality of Kalundborg).

Entering an ESCO-project does require certain in-house competences in order to manage tenders and legal questions about contracts. If these competences are not present, and if the building volume selected for the ESCO-contract is limited, the transaction costs might get very high, and so might the overall costs per $\mathrm{m}^{2}$. For municipalities with small in-house staff, it is principally possible to aggregate their projects and their in-house expertise and contract together (bundling of projects), but there have no such attempts yet amongst Danish municipalities. Another municipality (Vallenbæk), also using a basic approach, explains that due to the small size of the municipality, they are used to outsourcing many of their operations to private parties; therefore, the basic ESCO-concept was well suited for the challenge of improving the energy efficiency in their buildings. The collaboration ability of the ESCO-provider had a high priority in the tendering process, as a good collaboration with the supplier would reduce transaction costs related to negotiations on the baseline, as the municipality would be carrying out maintenance and smaller renovations on the buildings parallel to the ESCO-project.

Another characteristic of the first ESCO-projects, mainly using a basic approach, is that only a limited number of the municipal buildings are included in the project. As an example, the municipality of Vallensbæk, which has the highest guaranteed energy savings amongst the ten municipalities started their ESCO-project with a screening of all their 48 municipal buildings, but decided only to include the 20 most profitable buildings, i.e., buildings with a large potential for energy savings. This enabled a contract with large guaranteed energy savings, which reduces the payback time and makes the project more politically attractive. Amongst the municipalities using a basic approach, only two municipalities (Middelfart and Gribskov) have included all or a majority of the total municipal building volume.

\section{The integrative ESC-approach:}

This idea in this approach is to make energy savings with a short payback time finance investments in general building improvements. The "low hanging fruits" such as better energy regulation, adjustments of ventilation etc. are combined with "high hanging fruits" such as improvements on the building envelope, indoor climate and renewable energy sources (solar panels, PVs, heat pumps, etc.). Such projects require major investments and give longer payback periods, but they typically include a wider segment of the municipal buildings. Four of the ten municipalities (Høje Taastrup, Kerteminde, Sorø and Halsnæs) have used an integrated approach, where improvements such as improving the indoor climate, improving and insulating the building shell (facades, roof, windows), solving PCB-problems, and integrating renewable energy sources, such as PV's and heat pumps, have been included in the contract. As illustrated in Figure 1, the total investments and investments per $\mathrm{m}^{2}$ are relatively large in these municipalities, but the guaranteed savings are not systematically higher compared to municipalities having used the basic approach. The reason for this is that parts of the costs 
are not used explicitly on energy savings, but on other building features, such as improving indoor climate, installing PV's, etc., that does not reduce the energy consumption in the buildings, as well as including buildings with less potential in the ESCO-portfolio. Therefore it should be emphasized that in the integrated approach energy savings measures should be distinguished from facility refurbishing or renovation measures.

As a contrast, some of the municipal ESCO-projects using the basic approach include only buildings with the highest energy saving potential, which gives a higher guarantee of success. Compared to the basic ESCO-approach, it requires more work by the municipal administration, more local adaptation in terms of coordination between improvements of installations and buildings, and more innovative thinking about how to design the ESCO-contract. Whereas the basic approach can be used similar to an outsourcing-project, where the guaranteed energy savings can be defined early in the project, the integrated approach demands a larger degree of partnership between the municipality and the ESCO-provider, as the projects becomes more complex. A guarantee from the outset is attractive, but might also prevent more ambitious goals and innovative approaches being defined by the municipality in the pre-tendering phase. If they at the outset allow a more open discussion about the ambitions with the ESCO-project, it is likely that they will formulate more ambitious or integrated projects, where the guaranteed savings are defined through the tendering process, as one out of different targets. Therefore, the integrated approach might not be a formulated strategy at the outset, but might emerge along the process of defining the tender.

In the municipality of Høje Taastrup, the preparations for ESCO-contracting showed that the buildings were in a better shape than expected, which made it difficult to find the $15 \%$ energy reduction that was the target. Therefore, they had to "climb up the tree for the high-hanging fruits", by including solar panels on the town hall in the contract. The city council had to accept that the payback period was extended from 15 to 20 years, which according to the civil servant was a great challenge. The municipality of Halsnæs started out with a conservative aim of $15 \%$ savings that they were certain that they could find. However, persons from other parts of the administration that were invited to discuss the tender raised the question, why the goals were not more ambitious. This led to a new project description, with more ambitious goals, including that $15 \%$ of the reductions should come from renewable energy, and 35\% from improvements of the building envelope.

Many municipalities will see the ESCO-project as an opportunity to make the energy savings finance a general upgrade of the buildings, reducing the maintenance back-log. However, if the politically accepted payback-time is limited, this can be a difficult task, as expressed by one municipality:

“...it takes many improvements with short payback periods to enable inclusion of windows, walls, doors and all the other things with a long payback period." (officer, municipality of Sorø).

There are however signs that the city councils are beginning to more ambitious in the accepted pay-back times, rising from typically 10 years to 15,20 or 25 years. This has made several municipalities that started off with a basic ESCO-approach start planning an "ESCO 2", with an integrated approach. 


\section{The strategic ESCO approach:}

In this approach, the ESCO-concept is used more broadly to identify sustainable strategies for the municipality, using public-private partnerships, applying policies of "urban climate governance", and disseminating the ESCO-concept to other areas such as infrastructure and private buildings. It also might lead to new ways of thinking about the role of the municipal facility management in developing local competencies in energy retrofitting, for instance asking less as a local authority, and more as facilitator or networks between different stakeholders involved in. Such examples are primarily seen among Danish spearheads of ESCO-contracting, including the "ESCOmmune" collaboration. All three municipalities have ambitions to develop local competencies among local SMEs in energy renovation.

Three of the first municipalities to introduce ESCO-contracting have developed a collaboration on ESCO (Middelfart, Kalundborg and Gribskov), and can be seen as the Danish spearheads of ESCO-contracting. Attracting external financing to develop a handbook on ESCO-contracting and other activities to promote ESCO in municipalities has helped them to develop strategic initiatives on ESCO-contracting. All municipalities see ESCO as a step towards wider goals. This includes for instance ambitions to be an international first-mover on energy efficiency (Kalundborg), or on ESCO-contracting on other building types: private schools, other public buildings, social housing, and private building owners, where the municipal FM organisation will act as the 'network facilitator' (Middelfart). Also, ESCO-contracting can lead to considerations of the future municipal building portfolio, including the issue of "space management", or the future FM organisation (Gribskov municipality). Furthermore, all three municipalities have ambitions to develop local competences amongst Small and Medium Sized Enterprises (SMEs) and local enterprises on energy renovation, which is highly needed. For the three 'ESCO spearheads', the energy-retrofitting projects themselves have been rather simple, but they have been implemented in a strategic context that allows the experience from ESCO-contracting to be disseminated on an urban scale, as a planned learning process on energy retrofitting and increasing public-private collaboration. Moreover, all three municipalities are considering a new round of ESCO-contracts, based on the lessons learned in the first and basic ESCO-project.

\subsection{Comparing Approaches}

There are features related to the different approaches that make them attractive in different respects; generally, it is a well-known argument, that energy savings and building improvements should be better integrated, in order to achieve "deep renovations". Also, it might more efficient to carry out all improvements at once, instead of doing it in several turns. However, integrated approaches might be complex for smaller municipalities, and might be difficult to convince politicians about, especially for those who are not experienced in energy savings and climate policies. As an alternative, the basic approach have the advantage of being relatively easy to start up, and might act as a "stepping stone" in the development of more integrated concepts, as well as establishing confidence on the concept, the procedures, the operators, etc. From an economic point of view the integrated approach would probably look more attractive, but from an organizational point of view, the basic approach might be easier to implement. We argue that carrying out ESCO-projects include a potential learning process for the whole municipality, which might spark off political interest in energy savings, building improvements 
and $\mathrm{CO}_{2}$-reductions and eventually lead to a strategic approach. A strategic approach might not necessarily be formulated explicitly, but we see several municipalities linking ESCO-contracting to other initiatives such as climate plans, public-private partnerships, organizational changes, etc.

\section{Drivers and Barriers for Using ESCO}

There are different viewpoints on ESCO-contracting in Denmark, especially amongst Danish municipalities about the possible benefits of using ESCO-projects. In the following we will first present the benefits, as expressed by municipalities using the ESCO-model, and other stakeholders being in favour of the model.

\subsection{Motivations for Municipalities to Enter ESCO-Contracting}

\subsubsection{Capacity and Speed}

A main reason for many municipalities to carry out energy retrofitting of the municipal buildings as ESCO-contracting is that it would have been impossible as an in-house effort; many, especially smaller and medium-sized municipalities, have reduced their staff and maintenance budgets over time, partly resulting in a more outsourcing. Danish municipalities have in recent years been under large pressure for budget savings, and the maintenance of municipal buildings has been an oft-used place to find the savings. As the municipal reform in 2007 led to merge of many municipalities, and subsequently a change in the municipal facilities management organisations, the situation is that many municipal administrations are facing (a) a "new" and often unknown building stock; (b) new personnel in the facilities management organization; (c) a poorly maintained building portfolio; (d) limited staff and budgets; and (e) an increasing demand for implementing energy savings in the municipal buildings.

In our interviews on ESCO-contracting, many municipalities argue that it would have been completely impossible to carry out a retrofitting of the whole municipal building portfolio using their own staff only. It would, theoretically, be possible to hire more staff for the assignment, but it would require that the municipality could keep them occupied after the retrofitting was completed, or reducing the staff again, which would be difficult. As one municipality explains:

"It would take a long time to establish an organisation that could manage an assignment like that,

and we would have to start to downsize it almost as soon as we had started" (civil servant, municipality of Vallensbæk).

In this respect, ESCO-contracting fits has been a welcome possibility for several municipalities. Our analysis of the municipalities using ESCO-contracting shows that it is mainly small and medium-sized municipalities, which supposedly have similar small in-house FM-staff [12]. This supports the assumptions that the lack on in-house capacity is a main reason for municipalities to take up ESCO-contracting.

Even if the municipality had the necessary staff, the ESCO-contract would typically allow them to carry out the retrofitting faster. Also the budgets for financing retrofitting as an in-house-approach is typically step-wise, allowing only as step-wise improvement of the building portfolio, whereas the financing in an ESCO-project is an up-front investment on the whole building stock, but also an instant, or faster, improvement of the buildings, resulting in savings from "day one". As an example, 
one municipality stated that it could have had DKK $1 \mathrm{~m}$ per year (EUR 130,000) for an in-house retrofitting over the coming years, but the ESCO-contract gave them DKK $68 \mathrm{~m}$ (EUR $9 \mathrm{~m}$ ).

The strength of this approach is that energy in buildings is reduced from "day one"; The ESCO-provider mobilizes energy retrofitting in a short time, and start saving energy almost immediately. The in-house approach operates with a smaller in-house staff, which prolongs the period of analysis before building retrofitting is implemented, and energy savings are reached. As Colburn and Walawalkar [9] argue:

"The "opportunity cost," or "cost of inaction," is often overlooked at first by the owner. Two years of no implementation of work waiting for budget and work sequence approvals can be a real "loss" compared to implementing a project swiftly..."

A survey amongst Danish municipalities on energy saving initiatives in own buildings shows that the implementation time for in-house projects is in average 6.3 years, and in ESCO-projects 2.2 years. Investments in in-house projects are in average $14 € / \mathrm{m}^{2}$, in ESCO-projects $45 € / \mathrm{m}^{2}$. Energy savings in in-house projects are in average 13.8\%, and in ESCO-projects 21.1\% [13], see Figure 2. These figures indicate that ESCO-projects actually lead to more efficient output, besides giving some municipalities the option for retrofitting the building portfolio, which would have been practically impossible as an in-house project.

Figure 2. Investments, implementation-time and obtained savings in energy saving projects, as stated by municipalities having carried out in-house respectively ESCO-contracting projects on their own buildings (source: [13]).

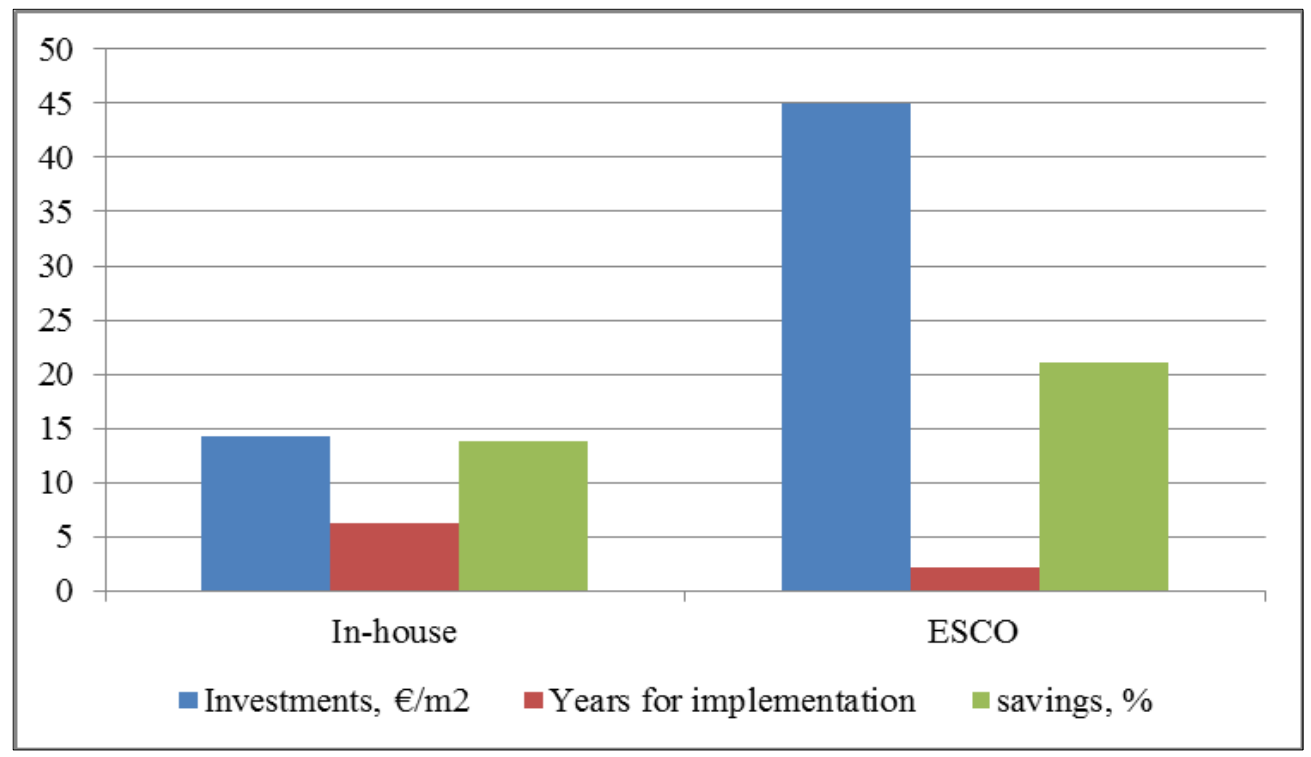

\subsubsection{Focus on Operation and Output}

In contrast to traditional client-supplier relations in the building sector, ESCO-contracts have a long-term perspective, integrating implementation of energy efficiency measures in the building phase with the operation phase of the buildings. Traditionally, contractors implementing retrofitting are in practice not responsible for the expected goals actually are being met in the operation phase, which has 
been a concurring frustration for many municipalities, as well as other types of clients. Unlike PPP-contracting, which has addressed this problem, but has not been used much in a Danish context, the ESCO-contracting represents a solution to address this challenge in practice. This is represented by three elements in the ESCO-concept: The guarantee on energy savings defined in the contract, the long operation period (typically $8-10$ years) and the incentive to motivate and train staff and users in the buildings. These elements are often referred to as a great achievement by the municipalities using ESCO-contracting. There are, however, also many examples on municipalities using an in-house approach that include these elements in their efforts, or instance to focus on training of staff, implement systematic monitoring systems on energy consumption in the municipal buildings, or establishing economic motives for municipal institutions to reduce energy consumption.

\subsubsection{Enabling Climate Goals}

It is noteworthy that ESCO-contracting has appeared almost parallel to the strong political focus on climate issues and energy reductions that has emerged since the early 2000nds. Out interviews with municipalities having signed ESCO-contracts confirms that political ambitions on climate reductions and energy savings have been strong drivers for the ESCO-contracts, as several municipalities have signed voluntary agreements on this. Agreements such as signing up as a "Climate Municipality" or signing the "Curb-cutter" deal introduces climate goals that present great challenges for the municipalities, but also a political acceptance to pursue energy savings. Reducing energy consumption by $2 \%$ p.a. is a challenge that requires extraordinary initiatives:

"We could save $2 \%$ a couple of years, using our own municipal finance. But after that it would become difficult. $2 \%$ per year is actually very ambitious...but then one of our consultants mentioned ESCO-contracting as an opportunity" (officer, municipality of Halsnæs).

On the other hand, there are also examples on ESCO-contracting being used in municipalities that are not politically very engaged in the climate agenda. Here, ESCO-contracting is seen as a way of being able to do something on energy retrofitting, without having to engage very much in it.

"If you had politicians that were really engaged, then you were already rolling, and you just needed to go on, instead of starting from scratch. But in our case it is better with an ESCO-project, then you can see what you get for your money" (officer, municipality of Kerteminde).

In this way, the increase in ESCO-contracting reflects a growing political focus on climate policies and energy reductions in Danish municipalities, which however also encourages other types of initiatives to meet these challenges, primarily as an in-house approach.

\subsection{Barriers for ESCO}

The skepticism expressed towards ESCO-contracting from municipalities and other stakeholders (consultants, NGO's, politicians, etc.) are both based on a general preference that municipalities should carry out the improvements by themselves, and some critical views on the ESCO-model. In the following we will summarize these arguments. 


\subsubsection{In-house Instead of ESCO}

One of the main arguments against ESCO-contracting is that it is more profitable for the municipality to complete the energy-efficient retrofitting themselves, as an in-house project [14,15]. Many argue that if the municipality itself completes the energy-retrofitting, competences will stay in-house.

"The companies offering ESCO-contracts with the municipalities want to get a hold on the long end, and we are not interested in that" (quote from a leader of the building section in a municipality who has rejected ESCO-contracting).

Here, the politicians found it very important to have a more skilled facility management organization afterwards, which they thought was better achieved if they carried out the energy retrofitting themselves. It was argued that the municipal in-house knowledge about the buildings means that you know exactly where to start implementing renovation-initiatives, start saving money from "day one" and also saves the salary of consultants. Moreover, the municipality argues that the in-house approach gives them full control over what technical solutions to implement, thereby tailoring the energy-saving solutions to the different type of buildings. This represents an often mentioned viewpoint, that the ESCO-providers are prone to use standardized solutions like expensive CTS technology, which the clients have little influence on. However, the typical approach in most ESCO-contracts is that the municipalities chooses the solutions that they want from a catalogue, presented by the ESCO-provider, where each solution has a guarantee of a certain energy saving.

\subsubsection{Transaction Costs}

Transaction costs is another well-known barrier for ESCO-contracting $[2,16]$ and PPP in general. If transaction costs rise, e.g., related to due diligence or to contract formulation, the volume of the contract also needs to be proportionally higher to maintain the net benefit. As stated by Sorrell, ESCO-contracting is expected to decrease production costs, but increase overall transaction costs [16]. In theory, the client would only enter ESCO-contracting if the reduction production costs would be larger than the increase in transaction costs. An important aspect of transaction costs is that simple ESCO-contracts generally have lower transactions costs, whereas as transaction costs will rise with increased complexity of the ESCO-contract. Complex contracts might make it more difficult to negotiate contract terms, establish monitoring systems and determine the influence of external factors on the energy-performance. Complex contracts also increase the asymmetry between the contractor and the client, for instance for the client to argue whether claims from the ESCO-supplier on reduced performances are due to external factors [16]. An example of such an asymmetry between the client and the contractor is well described by Backlund and Eidenskog [10]. In the Danish ESCO-contracts, the ESCO-provider delivers the model for the $\mathrm{M} \& \mathrm{~V}$-procedure, as no standard for $\mathrm{M} \& \mathrm{~V}$ exists, meaning that there is a risk of the negotiations on baseline-corrections being asymmetric in favor of the ESCO-provider.

Transaction costs can be relatively reduced by "bundling", meaning that a number of similar buildings types are prepared for a total tender, reducing the net transaction costs [6]. To avoid too high transaction costs, the minimum volume for an ESCO-project in the Danish context is assessed to 10-15 million Danish kroner. (1.5-2 million $€)$ [15]. The average ESCO-project is approximately 
5.5 million $€$ in volume, and therefore well beyond the critical limit. The Danish municipal reform in 2007 made it easier for the municipalities to "bundle" buildings for ESCO-tender, as their building portfolio has increased.

Other types of transaction costs, also well-known from the ESCO-literature, are negotiations about actually achieved energy savings, compared to the situation before the implementation of the measures (the baseline), as well as the costs for measurement and verification (M\&V) [3,4,17]. An often used argument against ESCO-contracting is that it will require many internal resources for negotiating baseline, and that an in-house approach will make it easier to coordinate energy saving initiatives with the ongoing maintenance of the buildings. The baseline of the savings has to be negotiated currently, as the municipality makes changes in the buildings, e.g., changes windows, expands a school or sell a building, or the school itself buys new electronic equipment. Such changes influence the energy performance of the building, and therefore have to be kept out of the contract. The assessment of how much such changes influence the consumption is naturally an object for negotiation between the ESCO-provider and the municipality. Many municipalities argue that this will be very time-consuming and demanding, and — as in Germany [17] — therefore causing some reservation towards the ESCO-model. A general perception is that an ESCO-project will actually require a full-time civil servant just to negotiate the baseline. This, however, is questioned by other observers; in the upstart and implementation phase there might be negotiations on a number of issues, but as the buildings goes into operation, the negotiations typically takes place during regular meeting, e.g., four to six times per year.

Generally, the lack of experience with tendering, PPP-collaboration, legal contract management etc. is a risk, that might increase the transaction costs. Lately there have been examples on tenders on ESCO-projects that have been cancelled, as they did not fulfill specific requirements, which illustrate that there are real risks related to ESCO-projects.

\subsubsection{Not Integrated Efforts}

Some studies have questioned the usability of ESCO-contracting to implement integrated energyand building retrofitting projects [17,18]. Also in practice, it is often argued that ESCO-projects include only energy savings with short pay-back times, and rarely energy savings to the building shell (facades, roofs, windows etc.). Typical arguments are:

"ESCO-suppliers are only interested in energy savings with short pay-back time (the low-hanging fruits)" or "ESCO-contracting is not suited for deep renovations, i.e., projects aimed at integrating energy savings and general retrofitting of the building such as improving facades, windows, the building interior, indoor climate etc."

As illustrated however from the current municipal ESCO-contracts, there are several possibilities for carrying out ESCO-contracts with integrated efforts. The depth of the renovation in the ESCO-project, however, is more a result of the political decisions about accepted pay-back times. If only pay-back times on 10 years are accepted politically, it is very difficult to integrate building-related improvements, as they typically have pay-back times on 20-30 years. Moreover, there is no evidence that municipalities carrying out in-house with projects pay-back times on 10 years are more interested in building-related improvements. As the ESCO-provider is paid with a certain percentage of the total 
investment, there is no reason why he should not be interested in integrating building-related improvements in the contract. There has however been a change in the political understanding and prioritization of energy savings in the municipalities, which in many municipalities has led to acceptance of longer pay-back times, typically from 10 years to 15, 20 or even 25 years, often with inspiration from municipalities who have actually done this (like the municipality of Halsnæs). This gives the municipal building administration possibilities of defining new types of projects, and many municipalities are therefore planning an "ESCO-2", with more ambitious goals than the first ESCO-project.

Consultants and ESCO-providers see the more integrated approach as the future trend. A main challenge is that the guarantee in an ESCO-project also might become a straitjacket that hinders a more innovative and ambitious ESCO-contract, for instance regarding the volume of buildings and goals included in the contract. A traditional way to manage the tendering process is that the municipalities, by help from their traditional consultant, estimates a level of energy savings within a politically defined payback time, and use these key-figures to formulate the tender. If the tender include guaranteed savings and a limited pay-back time from the outset, it prevents a discussion between the client and the ESCO-provider on the project possibilities after the ESCO-supplier has been selected. As formulated by an ESCO-provider:

"You decide whether you want to open up for flexibility or you just want to complete a basic project, you do it by writing in your tender that the payback time should be 8 years-you don't have to write more, then it's closed." (ESCO-provider).

As a consequence, ESCO-providers and consultants advocate for partnerships instead of guarantees, and see barriers as being more cultural than technical.

"In Denmark we are used to buying a commodity. But if you want to get the most out of it, you should buy a partnership. Thus we preach 'partnership' in the tender, and to think flexibility. It is not legislation hindering this, it is culture." (ESCO-provider).

The issue - as well as other central issues on ESCO-contracting - is related to the question of collaboration between the client's internal organization and the ESCO-provider. Much of the skepticism comes from the internal organization that might see the ESCO-provider as a competitor to their own function, or see it as an indirect critique that the internal organization has not delivered on providing energy efficient buildings. When it comes to integrated projects, where energy efficiency measures and general building improvements have to be carried out, it is necessary for the internal organization to collaborate closely with the ESCO-provider. Here it is necessary to see the ESCO-project as a partnership, instead of an outsourcing. As argued in [10], in-house competences and ESCOs should not be seen as contradictions, but as two concepts reinforcing each other. Municipalities involved in ESCO-contracting are generally aware of internal capacity building as a central part of the project, both in the short term and in the long term. The ESCO-project might be seen as a first step in developing a strong in-house capacity over time. Also, we see no evidence that municipalities entering ESCO-contracting tends to reduce their internal staff; on the contrary, some municipalities are even expanding, as the ESCO-projects tends to bring political focus on public buildings and the climate agenda. 
Below we have summarized strengths and motivations, respectively the barriers and challenges of using the ESCO-model, based on interviews with informants, and on our analysis of the municipalities ESCO-projects:

\section{Strengths and motivations}

- Capacity and speed: Allows small municipal FM-organisation to manage large building retrofitting;

- Guarantee for energy savings is politically attractive;

- Energy savings from 'day one' (compared to step-wise renovation through in-house efforts);

- Helps municipality to ensure climate goals;

- Focus on operation and output (as a contrast to in-house projects where verification and monitoring is typically weaker or absent);

- Include training of in-house organisation;

- ESCO-contracts reduces the risk of reductions in future investments in energy savings due to possible changes in political priorities.

\section{Barriers and challenges}

- Transaction costs in relation to tendering, contract management and M\&V-increase with the complexity of the ESCO-contract;

- Coordination between energy retrofitting and building maintenance regarded easier with in-house models;

- Municipalities have limited experience with long-term collaboration;

- Accept from in-house organisation and FM-staff;

- Some municipalities fear "loss of control" on solutions, and that learning is kept with ESCO-providers;

- Uncertainty on managing changes in future building portfolio (e.g., if municipality want to sell buildings in contract period);

- $\quad$ Lack of detailed knowledge about ESCO-model in municipalities.

In the following section we will discuss possible steps to taken in order to reduce barriers $\mathrm{f}$ or ESCO-contracting, especially formulation of national policies with inspiration from the Swedish ESCO-market.

\section{Increased Promotion of ESCO?}

The study of development of the ESCO-market in Denmark illustrates on one hand some obvious advantages in using the ESCO-model on municipal buildings, but on the other hand it also illustrates some reasons why ESCO-contracting is not embraced by all municipalities. The question is whether the national state could or should do more to promote ESCO?

\subsection{Political Initiatives}

Several authors have suggested different initiatives for the national states to encourage the use of ESCO-contracting $[2,6,19,20]$. This might include a number of different measures, from procurement adaptation and standard contracts to financial mechanisms such as subsidies, tax advantages, changes 
in laws, information, etc. [19]. On a regulatory level, the initiatives in Denmark to reduce transaction costs have been limited. A standard contract for municipal ESCO-contracts has been developed [21], but we have no reports on municipalities actually using it. In Sweden the state has concluded that there is no need for such an initiative, as the market is already well functioning [20]. Also, as stated by Sorrell, there is little evidence that measures such as model contracts and standardized M\&V-schemes actually are able to reduce transaction costs [18]. Instead, we suggest in line with Backlund and Eidenskog [10], that ESCO-contracting is basically a matter of trust between the client and the contractor, and that long-term ESCO-contracts are likely to increase this trust. Therefore municipalities should be aware of the importance of a good collaboration spirit with the ESCO-provider in preparing tendering and choosing ESCO-provider.

Besides formal regulations, institutional capacity building can be an important tool for developing an ESCO-market [2], as for instance in Austria, Germany and Sweden. In Sweden, an Energy Performance Contracting (EPC) forum was formed in 2004 with the aim of creating contact between public building owners, consultants and ESCO-providers, and communicating experience, as well as collecting and communicating experience gained from EPC-contracting. Evaluations have later shown that the EPC forum has had a central role for the development of EPC in Sweden, by informing different actors about EPC and creating confidence in the concept [5]. In contrast to these countries, such institutional capacity building has not taken place as a coordinated effort in Denmark. Different initiatives have, however, contributed to it, including promotion of ESCO-contracting on a series of workshops, support to municipalities that consider ESCO-contracting, collection of knowledge and "best practice" etc., combined with disseminating knowledge of ESCO-contracting, monitoring development and experience in Danish municipalities, informed on "best practice" and finally a number of R\&D projects on ESCO-contracting, including experience from other countries.

\subsection{Market Development}

The development of the Danish market has to large extent benefitted from the Swedish and German market experience. At the time when the Danish market emerged in 2007, about 20 Swedish municipalities had already signed an ESCO-contract. Many ESCO providers (such as Schneider electric, Siemens and YIT) have built their competences and gained experience on the Swedish market, and afterwards applied it on the Danish market. This has given Danish municipalities more confidence in ESCO-contracting, as the providers could refer to cases from similar municipalities in Sweden. Also, different ESCO-providers have been actively promoting ESCO-contracting through repeatedly visits to the municipalities. On the demand-side, many clients (Danish municipalities) have arranged study trips to Swedish and German municipalities, in order to collect first-hand experience on their ESCO-projects, and gain more confidence with the concept. Moreover, the municipalities have collected information and knowledge about ESCO-contracting from different informal sources, for instance talking with other municipalities, meetings with ESCO-providers, from the media and others sources.

\subsection{Standardization or Flexibility?}

In spite of the large influence from the Swedish market, the Danish market has, according to our informants, its own characteristics. In the Swedish market, being the most mature market in 
Scandinavia, ESCO-contracting has to a high degree become a "standard commodity" and the ambitions for using ESCO-contracting in a more innovative (integrated and strategic) way, is limited. Typically, ESCO-contracts are run as projects in the property administration, and receive limited attention. In Denmark, as a contract, the ESCO-projects are often highly politically profiled, as a part of the municipalities' climate agenda. There is no doubt that the political focus on climate policy and energy savings has played a large role for the development of the ESCO-market, partly sparked off by the COP15-meeting in Copenhagen in 2009, and partly by the political framework for motivating municipalities for energy savings. This has encouraged municipalities to formulate climate strategies, and goals for energy reductions in own buildings, and in the municipalities in general. About $80 \%$ of the municipalities have formulated energy goals [13], and about $2 / 3$ of the municipalities have signed a voluntary agreement as "Climate Municipality", which obliges the municipality to reduce energy consumption by $2 \%$ per year in the municipality as a whole.

The limited national capacity building, including standardization efforts, is perhaps reflected in the variation of ESCO-approaches being used by the municipalities. Often municipalities emphasizes that their ESCO-contract has been designed especially for their municipality, which reflects a large degree of local adaptation and subsequently a large degree of ownership to the project. This observation leads us to assume that the flexibility of the concept has been a main precondition for the growth of ESCO-contracting in Danish municipalities. The specific approach in the specific municipality is conditioned by the local factors such as the institutional history, the existing capacity of the municipal Facilities Management organization, the standard and specific challenges of the buildings, and the political and administrative visions of the municipality. For instance, the basic ESCO-approach in the municipality of Vallensbæk corresponds with a small municipal FM-organization being trained in outsourcing, with no ambitions of using ESCO-contracting as an explorative learning process. The strategic ESCO-approach in the municipality of Middelfart reflects an ambitious overall municipal strategy, where the concept of ESCO-contracting fits in well, and the strategic ESCO-approach becomes a potential strategic innovation: the municipality adopts the strategy of network governance hoping to generate green growth. The ambition of municipality of Kalundborg is to use ESCO-contracting as lever for being a "first mover" on energy retrofitting, setting the scene for national capacity building in this sector through establishing collaborations with industries in the municipality.

\section{Lessons Learnt}

Compared to the existing literature on energy service contracting, our research has found a number of similarities and some of the same issues at stake in the Danish market, as in other European ESCO-markets. However, we have also noted some differences on the Danish market, and as a contribution to the existing knowledge, we suggest two findings to be central:

- Firstly, the variation and flexibility of ESCO-contracting, as practiced in the Danish municipalities: This issue has not been researched to a large degree in other studies, although degrees of complexity [16] and integration [17] has been discussed, but mainly from a theoretical point of view. Our research suggests that ESCO-contracting could include simple as well as complex models, where future research could look into the practical results from the 
integrated models, including the development of production as well as transaction costs in such projects, as compared to more basic models.

- Secondly, the learning dimension of ESCO-contracting: The potentials for learning and innovation through ESCO-contracting has been relatively neglected in the research literature so far. We find in our research, however, that ESCO-contracting potentially has several potential implications for the way municipal FM-organizations manage their buildings, and for the way that the ESCO-concept is being developed to fit local needs. Where the research so far has focused mainly on policies on ESCO-contracting, we suggest that the emergence of ESCO-contracting as a result of other parameters should be an area for future research, for instance focusing on the challenges of municipalities for delivering results on a number of agendas, under changing organizational and financial conditions.

\section{Conclusions}

The studies of the Danish experiences using ESCO-contracting in public buildings illustrates that there is a large potential for using the model, which is empirically supported by the increasing growth of ESCO-contracting amongst the municipalities. Our studies of ESCO-contracting in public buildings suggest that ESCO-contracting, under the right circumstances, is an efficient tool for implementing energy savings in existing buildings. On one hand, many Danish municipalities have, motivated by political demands for energy reductions, formulated ambitious climate policies, and on the other hand the ESCO-providers have actively promoted ESCO-contracting. The absence of an active national ESCO-policy might have slowed the development, but it might also indirectly have contributed to a more market-based, flexible and context-dependent concept. What seems as a more or less uniform concept is revealed by a closer look to have many different drivers and logics for the municipalities. This includes issues on financing, on political commitment to pursue energy reductions, on defining the ESCO-tender and composing different types of initiatives in buildings, issues on competences and the internal municipal organization, and the traditions of carrying out public-private collaboration.

The Danish case illustrates that there are a number of cultural and ideological issues at stake by introducing the ESCO-model. As illustrated by the skepticism towards ESCO-contracting, there are degrees of misunderstandings and misinterpretations of how the ESCO-model actually works, which reflects that ESCO-contracting in many is a new type of collaboration for Danish municipalities, based on a long-term public-private partnership, which potentially might lead to learning in the public administration and more innovative approaches towards energy savings, building operation, collaboration etc. ESCO-contracting has the potential to become a learning process for the municipality, enabling and encouraging the public administration to work in other ways with public-private and public-public partnerships on energy savings.

\section{Acknowledgments}

The author would like to three anonymous reviewers for valuable and constructive comments on previous versions of the paper. We would also like to thank Center for Facilities Management for financial support to this project, as well as the many informants who have contributed to the data collection, and discussion of the results. 


\section{References}

1. The European Parliament. Directive 2006/32/EC of the European Parliament and of the Council of 5 April 2006 on energy end-use efficiency and energy services and repealing Council Directive 93/76/EEC. Off. J. Eur. Union 2006, 114, 64-85. Available online: http://eur-lex.europa.eu/ LexUriServ/LexUriServ.do?uri=OJ:L:2006:114:0064:0064:en:pdf (accessed on 24 April 2013).

2. Bertoldi, P.; Boza-Kiss, B.; Rezessy, S. Latest Development of Energy Service Companies across Europe-A European ESCO Update; European Commission, Institute for Environment and Sustainability: Ispra, Italy, 2007.

3. Singh, J.; Limaye, D.; Henderson, B.; Shi, X. Public Procurement of Energy Efficiency Services: Lessons from International Experience; The World Bank: Washington DC, USA, 2010.

4. Langlois, P., Hansen, S. World ESCO Outlook 2012; The Fairmont Press, Inc.: Lilburn, GA, USA, 2012.

5. Forsberg, A.; Lopes, C.; Öfverholm, E. How to Kick Start a Market for EPC. Lessons Learned from a Mix of Measures in Sweden. Available online: http://www.eceee.org/ conference_proceedings/eceee/2007/Panel_2/2.030/paper (accessed on 24 April 2013).

6. Marino, A.; Bertoldi, P.; Rezessy, S. Energy Service Companies Market in Europe-Status Report 2010; EUR 24516 EN; European Commission, Joint Research Centre, Institute for Energy: Ispra, Italy, 2010. Available online: http://publications.jrc.ec.europa.eu/repository/bitstream/111111111/ 15108/1/jrc59863\%20real\%20final\%20esco\%20report\%202010.pdf (accessed on 24 April 2013).

7. Kern, K.; Alber, G. Governing Climate Change in Cities: Modes of Urban Climate Governance in Multilevel Systems. In Proceedings of Competitive Cities and Climate Change, OECD Conference, Milan, Italy, 9-10 October 2008; Chapter 8, pp. 171-196. Available online: http://www.oecd.org/gov/regional-policy/50594939.pdf (accessed on 27.04.2013).

8. Bulkeley, H.; Schroeder, H.; Janda, K.; Zhao, J.; Armstrong, A.; Chu, S.Y.; Ghosh, S. Cities and Climate Change: The Role of Institutions, Governance and Urban Planning; University of Oxford: Oxford, UK, 2009; p. 92.

9. Colburn, B.; Walawalkar, R. ESCOs and In-house managers: A winning team. Strateg. Plan. Energy Environ. 2005, 24, 39-56.

10. Backlund, S.; Eidenskog, M. Energy service collaborations - It is a question of trust. Energy Effic. 2012, doi:10.1007/s12053-012-9189-z.

11. Jensen, J.O.; Hansen, J.R.; Nielsen, S.B. ESCO in Danish Municipalities: Basic, Integrative or Strategic Approaches? In Facilities Management Research in the Nordic Countries: Past, Present and Future; Jensen, P.A., Nielsen, S.B., Eds.; Polyteknisk Boghandel og Forlag: Lyngby, Danmark, 2012; pp. 144-158.

12. Jensen, J.O.; Nielsen, S.B.; Hansen, J.R. ESCO in Denmark. In World ESCO Outlook 2012; Langlois, P., Hansen, S., Eds.; The Fairmont Press, Inc.: Lilburn, GA, USA, 2012.

13. Udbudsrådet. Energirenovering af Kommunale Bygninger [Energy Retrofitting of Municipal Buildings]. Udbudsrådet: Copenhagen, Denmark, December 2012. Available online: http://www.udbudsraadet.dk/fileadmin/user_upload/Rapporter/2012/Energirenoveringer_kommun ale_bygninger/Analyse_af_energirenoveringer_af_kommunale_bygninger.pdf (accessed on 24 April 2013). 
14. Ingeniørforeningen i Danmark (IDA). Survey om Energi Besparelser i Kommuner Med Brug af ESCO [Survey on Energy Savings in the Municipalities with ESCO]; Ingeniørforeningen i Danmark: Copenhagen, Denmark, 2010.

15. NRGi Rådgivning $\mathrm{A} / \mathrm{S}$. Undersøgelse af det kommunale arbejde med energibesparelser og udbredelsen af ESCO [Survey on the municipal efforts on energy savings and dissemination of ESCO]. Available online: http://www.goenergi.dk/aktuelt/offentlig/kommuner-flirter-med-esco (accessed on 23 April 2013).

16. Sorrell, S. The economics of energy service contracts. Energy Policy 2007, 35, 507-521.

17. Bleyl-Androschin, J.W. Conservation First! The New Integrated Energy-Contracting Model to Combine Energy Efficiency and Renewable Supply in Large Buildings and Industry. In Proceedings of European Council for an Energy Efficient Economy (ECEEE) 2011 Summer Study, Stockholm, Sweden, 6-11 June 2011.

18. Chong, E.; Le Lannier, A.; Staropoli, C. Achieving Energy Saving in the Public Sector through "Energy Performance Contracts": Is it the Right Tool? In Proceedings of European Council for an Energy Efficient Economy (ECEEE) 2011 Summer Study, Stockholm, Sweden, 6-11 June 2011.

19. Westling, H. Energy Performance Contracting will Improve Climate and Business. In Proceedings of European Council for an Energy Efficient Economy (ECEEE) 2003 Summer Study, St. Raphaël, France, 2-7 June 2003.

20. Backlund, S.; Thollander, P. The energy service gap: What does it mean? In Proceedings of European Council for an Energy Efficient Economy (ECEEE) 2011 Summer Study, Stockholm, Sweden, 6-11 June 2011.

21. Elsparefonden. Standarddokumenter for Udbud af Energitjenester [Standarddocument for Tendering of Energy Services], Version 02; Elsparefonden: Copenhagen, Denmark, 2009.

(C) 2013 by the authors; licensee MDPI, Basel, Switzerland. This article is an open access article distributed under the terms and conditions of the Creative Commons Attribution license (http://creativecommons.org/licenses/by/3.0/). 